\title{
The Relationship between insulin variable number of tandem repeats (INS-VNTR) -23 A/T and cytotoxic T- lymphocyte associated protein-4 (CTLA-4) +49 A/G polymorphisms with islet autoantibodies in persons with diabetes
}

\author{
Mohammad Khoshroo ${ }^{1}$, Mohammad Ebrahim Khamseh², Ali Akbar Amir Zargar ${ }^{3}$, Mojtaba Malek $^{2}$, Reza Falak ${ }^{1}$, \\ Mehdi Shekarabi**
}

Received: 5 Feb 2016 Published: 12 Dec 2017

\begin{abstract}
Background: Both genetic and environmental factors are important in pathogenesis of diabetes. Non HLA (Human Leukocyte Antigen) genes such as INS-VNTR and CTLA-4 in addition of HLA genes have influence on genetic susceptibility for diabetes mellitus. In this study the association of $+49 \mathrm{~A} / \mathrm{G}$ CTLA- 4 and $-23 \mathrm{~A} / \mathrm{T}$ INS-VNTR polymorphisms with diabetes and their association with islet autoantibodies were investigated.

Methods: Thirty four autoantibody positive adult persons with diabetes mellitus and 39 persons with Type 1diabetes mellitus (T1DM), 40 autoantibody negative Type 2 diabetes mellitus (T2DM) patients and 40 healthy controls were studied using Polymerase Chain Reaction-Restriction Fragment Length Polymorphism (PCR-RFLP) technique.

Results: The frequencies of $-23 \mathrm{~A} / \mathrm{T}$ INS-VNTR genotypes were not significantly different among study groups. It was shown that the distribution of the +49A/G CTLA-4 allele and genotype frequencies did not differ between T1DM patients, autoantibody positive adult patients and controls. With increasing CTLA-4 G allele and GG/AG genotypes, the frequency of Glutamic Acid Decarboxylase Autoantibody (GADA), Islet Cell Autoantibody (ICA) and Islet Antigen 2 Antibody (IA2A) positive patients were increased.

Conclusion: Our results suggest that susceptibility allele A of -23A/T INS-VNTR does not have any role in the pathogenesis of diabetes in our patients and susceptibility allele $\mathrm{G}$ of $+49 \mathrm{~A} / \mathrm{G}$ CTLA- 4 if not, has a small role in pathogenesis of diabetes in T1DM and autoantibody positive adult patients and in spite of significant increase in autoantibody negative T2DM group it does not have any role in disease pathogenesis.
\end{abstract}

Keywords: CTLA-4, INS-VNTR, Diabetes Mellitus, Autoantibodies, Polymorphism

Copyright@ Iran University of Medical Sciences

Cite this article as: Khoshroo M, Khamseh ME, Amir Zargar AA, Malek M, Falak R, Shekarabi M. The Relationship between insulin variable number of tandem repeats (INS-VNTR) -23 A/T and cytotoxic T-lymphocyte associated protein-4 (CTLA-4) +49 A/G polymorphisms with islet autoantibodies in persons with diabetes. Med J Islam Repub Iran. 2017 (12 Dec);31:83. https://doi.org/10.18869/mjiri.31.83

\section{Introduction}

The prevalence of diabetes is rising in the world population and aging, urbanization, lifestyle changes and obesity can increase its incidence. The incidence of T1DM is rising in parallel with the world wide rise in T2DM. Epide-

Corresponding author: Dr Mehdi Shekarabi, dr.shekarabim@gmail.com

1. Department of Immunology, School of Medicine, Iran University of Medical Sciences, Tehran, Iran.

2. Endocrine Research Center, Institute of Endocrinology and Metabolism, Iran University of Medical Sciences, Tehran, Iran.

3. Molecular Immunology Research Center, Tehran University of Medical Science, Tehran, Iran

4. Department of Immunology, School of Medicine, Iran University of Medical Sciences, Tehran, Iran \& Immunology Research Center, Iran University of Medical Sciences, Tehran, Iran. miological studies have shown that T1DM is not a childhood disease and an equivalent number of the cases diagnose in adult patients. The second group does not show typical characteristics of T1DM, yet has detectable islet

$\uparrow$ What is "already known" in this topic:

Genetic susceptibility to IDDM is encoded by several loci, one of which (IDDM2) maps to a variable number of tandem repeats (VNTR) minisatellite, upstream of the insulin gene (INS). The second, Cytotoxic T lymphocyte-associated antigen-4 (ctla-4) or IDDM12 is an important negative regulator of T-cell responses.

$\rightarrow$ What this article adds:

Allele A of -23 A/T INS-VNTR and allele $\mathrm{G}$ of $+49 \mathrm{~A} / \mathrm{G}$ CTLA-4 did not play a role in the disease pathogenesis. 
autoantibodies and disease progression toward insulin dependency occurs in a short period of time. This slowly progressing autoimmune diabetes is known a s "latent autoimmune diabetes in adults" (LADA) (1). Studies have shown that non HLA (Human Leukocyte Antigen) genes such as INS-VNTR and CTLA-4 in addition of HLA genes have influence on genetic susceptibility for LADA (2). The INS-VNTR has been broadly studied for association with T1DM, T2DM, birth size and the polycystic ovary syndrome (3). Also, this region is a susceptibility locus to LADA (4).

The insulin VNTR (INS-VNTR) is placed in 596 base pairs upstream (-596) of the translation initiation codon of the insulin gene on chromosome 11. The INS-VNTR includes differing numbers of a 14-15 base pair repeat and categorized into three allelic groups: 1- the short class I alleles consisting of 26-63 repeats 2-the intermediate class II alleles (approximately 80 repeats) and 3-the long class III alleles consisting of 141-209 repeats. The class II alleles have been seen mostly in black populations and are infrequently found in Caucasians. In addition to length polymorphisms, within the various repeat units, nucleotide sequences can be different. The polymorphisms of the INS-VNTR are not randomly distributed and have been grouped into lineages based upon sequence and length. Moreover, the INS-VNTR polymorphism is in strong linkage disequilibrium with several neighboring single nucleotide polymorphisms. One of these is a A/T polymorphism, which can be identified by the restriction enzyme HphI and is situated 23 nucleotides upstream of the insulin gene translation initiation codon. In Caucasian population the $-23 \mathrm{HphI} \mathrm{A}$ or T alleles can be used as surrogate genetic marker for class I and III VNTR alleles respectively $(5,6)$. Change in the other genes also is associated with LADA and T1DM. One of the candidate genes is CTLA-4, a negative regulator of the T cell activation. This gene has four exons and various polymorphisms have been reported at the promoter region and exon $1(7,8)$. Among CTLA-4 gene polymorphisms, single nucleotide polymorphism (SNP) existing in exon 1, a G to A transition at position $49(+49 \mathrm{~A} / \mathrm{G})$ leads to an Alanine to Threonine aminoacid substitution at the codon 17. This change has been associated with susceptibility to autoimmune diseases (7). The non-synonymous $+49 \mathrm{~A}>\mathrm{G}$ base substitution is responsible for Thr 17 Ala change. This amino acid substitution occurs in signal peptide region of molecule. In the endoplasmic reticulum, the molecule contains alanine at position 17 is abnormally glycosylated that leads to moving backwards of the molecules into the cytoplasm for degradation. This finally results in low amount of CTLA-4 (molecule contains alanine at position 17) at the cell surface and reduce the inhibitory function of CTLA-4 reported in patients with $+49 \mathrm{G}$ allele $(9,10)$.

Many studies have investigated +49 A/G CTLA-4 in Iranian persons with diabetes mellitus and other ethnic groups (11). As there is no existing data for Iranians, we examined for the first time the relationship between -23 A/T INS-VNTR polymorphism and diabetes in Iranian population. In addition, we investigated the relationship between -23 A/T INS-VNTR and +49 A/G CTLA-4 pol- ymorphisms with islet autoantibodies in our patients.

\section{Methods \\ Subject}

One hundred and twenty-six diabetic patients (T1DM 40 persons, phenotypically T2DM 84 persons and 40 persons without diabetes as controls) were enrolled between April and November 2014 in this cross- sectional study. Patient subjects were selected from the patients referred to Kamkar hospital in Qom, Iran. The study protocol was approved by the ethical committee of the Iran University of Medical Sciences, and written informed consent was also obtained from all of subjects. A questionnaire about age, age at diagnosis, gender, and family history of diabetes, education, exercise and smoking habits, and the duration of diabetes were completed by all participants. Also participants were interviewed and examined to determine characteristics and medical conditions by physician. Anthropometric evaluations were done by trained personnel and weight and height of each patient was measured and the BMI (Body Mass Index) was calculated using the formula body weight in kilograms divided by height in square meters. Patient subjects were divided into two groups of Type 1 diabetes (40 persons) and phenotypically Type 2 diabetes ( 84 persons). Classification was based on age at diagnosis and current treatment. Type 1 diabetes was defined by the disease onset in age 30 years or less and insulin requirement at the onset of disease. Type 2 diabetes was defined by onset in age 30 years or after and non-requirement to insulin at the diagnosis. Two patients were 27 and 28 years of age but did not clearly exhibit the clinical features of either type.

\section{Autoantibodies evaluation}

A blood sample of $6 \mathrm{ml}$ was drawn from each patient and control and centrifuged within 2 hours of collection. The sera were frozen at $-70^{\circ} \mathrm{C}$ until used. A serum sample obtained from each individual was used to determine the serum levels of autoantibodies including Glutamic Acid Decarboxylase Autoantibody (GADA), Islet Cell Autoantibody (ICA) and Islet Antigen 2 Antibody (IA2A) using ELISA technique. Serum autoantibodies levels were measured using specific ELISA kit (EASTBIOPHARM, HANGZHOU EASTBIOPHARM CO., LTD.) According to the manufactures protocol. Antibodies levels were defined by plating a standard curve derived from known concentrations of standards using absorbance readings at $450 \mathrm{~nm}$ on ELISA reader. The minimum and maximum detection levels for the GADA were $1 \mathrm{ng} / \mathrm{mL}$ and 300 $\mathrm{ng} / \mathrm{mL}$ respectively. Values above $50 \mathrm{ng} / \mathrm{mL}$ for GADA was considered as positive (12). The minimum and maximum detection levels for the ICA were $0.5 \mathrm{U} / \mathrm{L}$ and $150 \mathrm{U} / \mathrm{L}$ respectively and the minimum and maximum detection levels for the IA2A were $1 \mathrm{ng} / \mathrm{mL}$ and 300 $\mathrm{ng} / \mathrm{mL}$ respectively. Sera with ICA or IA-2A values above the mean plus three times the standard deviation of the 40 non diabetic control subjects were regarded as positive. Values above $30 \mathrm{ng} / \mathrm{mL}$ for IA2A and $20 \mathrm{U} / \mathrm{L}$ for ICA were considered as positive. All samples were measured in duplicates. 
M. Khoshroo, et al.

Table 1. Information on Primer Sequences, Restriction Enzymes, PCR Product Size and Digested Product Size

\begin{tabular}{|c|c|c|c|c|}
\hline Gene & Primer sequence used for PCR reaction & Restriction enzyme & $\begin{array}{c}\text { PCR Product } \\
\text { Size }(b p)\end{array}$ & $\begin{array}{l}\text { Digested product size } \\
(\mathrm{bp})\end{array}$ \\
\hline$C T L A-4$ & $\begin{array}{l}\text { 5'-AAC CCA CGG CTT CCT TTC TC-3' F CTLA-4 } \\
\text { 5'-ATA CAG AGC CAG CCA AGC CA-3' R CTLA-4 }\end{array}$ & BbvI & 463 & $\begin{array}{c}\text { A Allele: } 463 \\
\text { G Allele: } 244,219\end{array}$ \\
\hline INS-VNTR & $\begin{array}{l}\text { 5'-GCC ATC AAG CAG GTC TGT TCC-3'F INS } \\
\text { 5'-CGT GCC CAC CCT CTG ATG TA-3' R INS }\end{array}$ & HphI & 641 & $\begin{array}{l}\text { A Allele: } 234,231,136,40 \\
\text { T Allele:271,234,136 }\end{array}$ \\
\hline
\end{tabular}

\section{DNA extraction}

After autoantibodies screening, 151 subjects were selected. Peripheral blood samples of 34 antibodies positive T2DM, 40 antibodies negative T2DM, 39 T1DM and 40 antibody negative non diabetic controls were collected in $10 \mathrm{~mL}$ volumes by venous puncture and genomic DNA was extracted by non-enzymatic salting out method, as described previously (13).

\section{Genotyping and RFLP analysis}

At the INS-VNTR locus, alleles are known as class I ( 26 - 63 repeats), class II (about 80 repeats) and class III (141-209 repeats), with frequencies of approximately 0.71 and 0.29 for class I and III. The $-23 \mathrm{~A} / \mathrm{T}$ HphI polymorphism (rs689) was used as a surrogate marker for INS-VNTR genotyping, as both loci display a linkage disequilibrium higher than $99 \cdot 7 \%$ in Caucasian and Mongoloid populations (14).

Another candidate gene for $\mathrm{T}$ cell-mediated autoimmune diseases like T1DM is CTLA-4. In this gene, the main polymorphism is localized in exon 1 at position 49 $(A \rightarrow G)$, which encodes Threonine or Alanine, respectively. The CTLA-4 G allele has been associated with T1DM in many populations (15).

The target region of the INS-VNTR and CTLA-4 gene were amplified by polymerase chain reaction (PCR) with the forward primer 5'-GCC ATC AAG CAG GTC TGT TCC-3' and reverse primer 5'-CGT GCC CAC CCT CTG ATG TA-3' for INS-VNTR and the forward primer 5'AAC CCA CGG CTT CCT TTC TC-3' and reverse primer 5'-ATA CAG AGC CAG CCA AGC CA-3' for CTLA-4 (PCR-products size 641 and 463 bp respectively). Two primer pairs were designed using Oligo 5 Software and were blasted in NCBI website: http://www. ncbi.nlm.nih.gov/tools/primer-blast/. The designed PCR primers have been made by Cina Clon Company, Tehran, Iran. PCR reactions were performed by Ampliqon Inc. Master Mix (Cat No: 180303) in the final volume of $25 \mu \mathrm{l}$ and $20 \mu \mathrm{l}$ for INS-VNTR and CTLA-4 respectively. A 50 ng genomic DNA was amplified in PCR reaction containing of master mix, $0.6 \mu \mathrm{M}$ of each primer for INS-VNTR and $0.4 \mu \mathrm{M}$ of each primer for CTLA-4 and distilled water. The reaction mixture was first heated at $95^{\circ} \mathrm{C}$ for 5 min and amplification was done for 35 cycles in a PCR thermocycler by denaturation at $93^{\circ} \mathrm{C}$ for $30 \mathrm{~s}$, annealing at $56^{\circ} \mathrm{C}$ for $40 \mathrm{~s}$ and extension at $72^{\circ} \mathrm{C}$ for $40 \mathrm{~s}$ at each cycle and with final extension at $72^{\circ} \mathrm{C}$ for $10 \mathrm{~min}$ for amplification of the desired fragment of INS-VNTR. PCR conditions in a PCR thermocycler were denaturation at $95^{\circ} \mathrm{C}$ for $5 \mathrm{~min}$, followed by 35 cycles of denaturation at $93^{\circ} \mathrm{C}$ for $30 \mathrm{~s}$, annealing at $55^{\circ} \mathrm{C}$ for $40 \mathrm{~s}$, and extension at $72^{\circ} \mathrm{C}$ for 40 s with final extension at $72^{\circ} \mathrm{C}$ for $10 \mathrm{~min}$ for amplifica- tion of desired fragment of CTLA-4. The products were then kept at $4^{\circ} \mathrm{C}$ until further use. RFLP analysis was done using HphI and BbvI (ER1101 HphI and ER1451 BseXI Fermentas, Germany) in $15 \mu \mathrm{L}$ total volume. RFLP analysis for $-23 \mathrm{~A} / \mathrm{T}$ INS-VNTR was done by using HphI in $15 \mu \mathrm{L}$ total volume by mixing: $5 \mu \mathrm{l}$ of PCR product, $1.1 \mu \mathrm{l}$ $\mathrm{HphI}$ restriction enzyme solution (Fermentas), and $8.9 \mu \mathrm{L}$ nuclease-free water. The mixture was incubated at $37^{\circ} \mathrm{C}$ for 16 hours followed by heating at $65^{\circ} \mathrm{C}$ for $20 \mathrm{~min}$ for enzyme inactivation. RFLP analysis for +49 A/G CTLA- 4 was done using BbvI in $15 \mu \mathrm{L}$ total volume by mixing: $5 \mu \mathrm{L}$ of PCR products, $1.1 \mu \mathrm{L}$ of BbvI restriction enzyme solution, and $8.9 \mu \mathrm{L}$ nuclease-free water. The mixture was incubated at $65^{\circ} \mathrm{C}$ for 16 hours followed by heating at $80^{\circ} \mathrm{C}$ for $20 \mathrm{~min}$.

DNA fragments were resolved in $1.5 \%$ agarose gel at $80 \mathrm{~V}$. The gel was stained with ethidium bromide and the bands visualized in gel doc. For the A allele, four 271, 234, 136 and $40 \mathrm{bp}$ fragments and for the $\mathrm{T}$ allele, three 234, 231 and 136 fragments were resulted for -23 INSVNTR. For the G allele, digestion of the amplified $463 \mathrm{bp}$ product with BbvI enzyme resulted in 244 bp and 219 bp fragments and for the A allele one 463 fragment were resulted (Table 1).

\section{Statistical analysis}

Descriptive statistics (mean and SD) were reported for quantitative variables. Frequency distribution were expressed as percentage while significant tests were done with the t-test, ANOVA and correlations done by Pearson or Spearman.

Alleles and genotypes frequencies between patients and controls were analyzed by chi-square test. All analyses were performed using SPSS 16 Software. The $p$ values of $<0.05$ were considered significant.

\section{Results}

Of 84 (missed 16 serum samples of 100 initially samples) phenotypically Type 2 diabetes patients, 34 (40.47 $\%)$ were antibody positive. Clinical characteristics of study groups are presented in Table 2. Of 34 antibody positive T2DM patients $25(73.52 \%)$ persons were GADA positive, $26(76.47 \%)$ persons were ICA positive and finally $16(47.1 \%)$ were IA2A positive. Of 39 (missed one sample of 40 initially samples) T1DM, 11(28.20\%) were antibody positive. Of these, $10(25.64 \%)$ persons were GADA positive, $11(28.20 \%)$ persons were ICA positive and 5 (12.82) persons were IA2A positive. Genotype and allele frequencies of $-23 \mathrm{~A} / \mathrm{T}$ INS-VNTR and $+49 \mathrm{~A} / \mathrm{G}$ CTLA-4 in our study groups presented in Tables 3 and 4 respectively. The frequencies of -23 A/T INS-VNTR gen- 


\begin{tabular}{|c|c|c|c|c|}
\hline \multirow[b]{2}{*}{ Characteristics } & \multicolumn{4}{|c|}{ Group } \\
\hline & T1DM & $\begin{array}{l}\text { Autoantibody positive } \\
\text { T2DM patients }\end{array}$ & $\begin{array}{c}\text { Autoantibody negative } \\
\text { T2DM patients }\end{array}$ & Controls \\
\hline $\mathrm{n}$ & 39 & 34 & 40 & 40 \\
\hline $\mathrm{M} / \mathrm{F}(\%)$ & $20(51.28 \%) / 19(48.72 \%)$ & $13(38.2 \%) / 21(61.8 \%)$ & $16(40 \%) / 24(60 \%)$ & $22(55 \%) / 18(45 \%)$ \\
\hline Age (SD) y & $15.43(5.16)$ & $53.41(8.80)$ & $51.02(8.61)$ & $42.7(15.4)$ \\
\hline $\mathrm{BMI}(\mathrm{SD})$ & Not determined & $29.10(4.84)$ & $30.63(3.88)$ & $26.16(5.01)$ \\
\hline Hypertension (\%) & Not determined & $19(55.9)$ & $25(62.5)$ & $0.0(0.0)$ \\
\hline Family history of diabetes $(\%)$ & $18(46.15 \%)$ & $22(64.7)$ & $32(80 \%)$ & $0.0(0.0)$ \\
\hline Insulin dependency $(\%)$ & $39(100)$ & $10(29.4)$ & $13(32.5)$ & $0.0(0.0)$ \\
\hline Dislipidemia (\%) & Not determined & $15(44.1)$ & $16(40)$ & $0.0(0.0)$ \\
\hline Autoimmune diseases history & $1(2.56)$ & $6(17.6)$ & $7(17.5)$ & $0.0(0.0)$ \\
\hline \multicolumn{5}{|c|}{ Table 3. Genotype and Allele Frequencies of $-23 \mathrm{~A} / \mathrm{T}$ INS-VNTR in Study Groups } \\
\hline Genotypes (\%) & T1DM & $\begin{array}{l}\text { Autoantibody positive } \\
\text { T2DM patients }\end{array}$ & $\begin{array}{c}\text { Autoantibody negative } \\
\text { T2DM patients }\end{array}$ & Controls \\
\hline AA & $9 / 39(23.1)$ & $5 / 34(14.70)$ & $6 / 40(15)$ & $11 / 40(27.5)$ \\
\hline TT & $22 / 39(56.4)$ & $19 / 34(55.89)$ & $27 / 40(67.5)$ & $19 / 40(47.5)$ \\
\hline AT & $8 / 39(20.5)$ & $10 / 34(29.41)$ & $7 / 40(17.5)$ & $10 / 40(25)$ \\
\hline \multicolumn{5}{|l|}{ Allels (\%) } \\
\hline A & $26 / 78(33.3)$ & $20 / 68(29.41)$ & $19 / 80(23.75)$ & $32 / 80(40)$ \\
\hline $\mathrm{T}$ & $52 / 78(66.7)$ & $48 / 68(70.59)$ & $61 / 80(76.25)$ & $48 / 80(60)$ \\
\hline \multicolumn{5}{|c|}{ Table 4. Genotype and Allele Frequencies of $+49 \mathrm{~A} / \mathrm{G}$ CTLA- 4 in Study Groups } \\
\hline & \multicolumn{4}{|c|}{ Group } \\
\hline Genotypes (\%) & T1DM & $\begin{array}{c}\text { Autoantibody positive T2DM } \\
\text { patients }\end{array}$ & $\begin{array}{l}\text { Autoantibody negative } \\
\text { T2DM patients }\end{array}$ & Controls \\
\hline GG & $18 / 39(46.15)$ & $15 / 34(44.12)$ & $24 / 40(60)$ & $12 / 40(30)$ \\
\hline AA & $11 / 39(28.20)$ & $9 / 34(26.47)$ & $9 / 40(22.5)$ & $13 / 40(32.5)$ \\
\hline $\mathrm{AG}$ & $10 / 39(25.64)$ & $10 / 34(29.41)$ & $7 / 40(17.5)$ & $15 / 40(37.5)$ \\
\hline \multicolumn{5}{|l|}{ Allels (\%) } \\
\hline A & $32 / 78(41.02)$ & $28 / 68(41.18)$ & $25 / 80(30)$ & $41 / 80(51.25)$ \\
\hline $\mathrm{G}$ & $46 / 78(58.98)$ & $40 / 68(58.82)$ & $55 / 80(70)$ & $39 / 80(49.75)$ \\
\hline
\end{tabular}

otypes were not significantly different between T1DM patients, antibody positive T2DM patients, antibody negative T2DM patients and normal subjects (Tables 5, 6). The +49 A/G CTLA-4 risk genotype GG was most frequent in antibody negative T2DM patients $(60 \%)$, followed by T1DM patients $(46.15 \%)$, antibody positive T2DM patients $(44.12 \%)$ and healthy controls $(30 \%)$. The $+49 \mathrm{~A} / \mathrm{G}$ CTLA-4 AG and GG genotypes were associated with antibody negative T2DM patients (Tables 7,8 ). The dis- tribution of +49 A/G CTLA-4 genotypes and alleles frequencies based on chi- squared test did not differ significantly between T1DM patients, antibody positive T2DM patients and controls. The frequencies of +49 A/G CTLA4 genotypes and alleles were significantly different between antibody negative T2DM patients and healthy subjects at $\mathrm{p}<0.05$.

With increasing CTLA-4 G allele and GG/AG genotypes, the frequency of GADA, ICA and IA2A positive

\begin{tabular}{lcccc}
\multicolumn{5}{l}{ Table 5. INS-VNTR -23A/T Genotypes and Alleles Frequencies in Autoantibody Positive T2DM Patients and Controls } \\
\hline Par. & Autoantibody positive T2DM patients (n) & Controls (n) & Odds ratio (95\%CI) & p \\
\hline Genotypes & 5 & & & \\
AA & 10 & 11 & $0.45(0.14-1.473)$ & 0.183 \\
AT & 19 & 10 & $1.25(0.45-3.5)$ & 0.670 \\
TT & & & $1.4(0.56-3.51)$ & 0.472 \\
Alleles & 20 & 32 & $0.625(0.314-1.243)$ & 0.179 \\
A & 48 & 48 & $1.6(0.8-3.18)$ & 0.179 \\
T & & &
\end{tabular}

Table 6. INS-VNTR -23A/T Genotypes and Alleles Frequencies in Autoantibody Negative T2DM Patients and Controls

\begin{tabular}{lcccc}
\hline & Autoantibody negative T2DM patients (n) & Controls (n) & Odds ratio (95\%CI) & p \\
\hline & & & & \\
Genotypes & 6 & 11 & $0.46(0.153-1.41)$ & 0.172 \\
AA & 7 & 10 & $0.64(0.215-1.88)$ & 0.412 \\
AT & 27 & 19 & $2.30(0.93-5.70)$ & 0.07 \\
TT & 19 & 32 & $0.43(0.23-0.824)$ & 0.01 \\
Alleles & 61 & 48 & $2.31(1.21-4.41)$ & 0.01 \\
A & & & & \\
T & & & &
\end{tabular}


Table 7. CTLA4 +49A/G Genotype and Allele Frequencies in Autoantibody Positive T2DM Patients and Controls

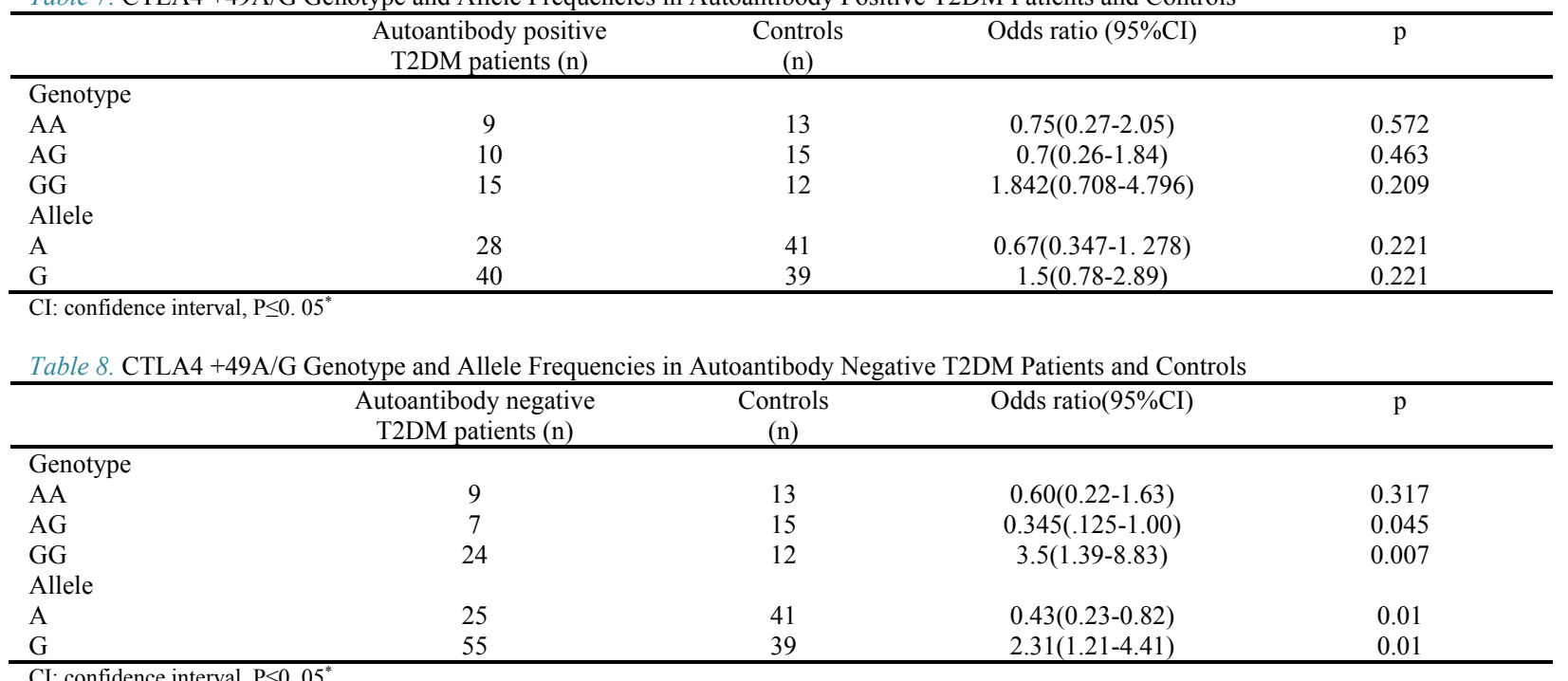

patients were increased (Figs. 1 and 3). In contrast, in GADA, ICA and IA2A positive patients, protective genotype INS-VNTR TT was more frequent (Fig. 2). There is no significant association between -23 A/T INS-VNTR and +49 A/G CTLA-4 genotypes and alleles and number of antibodies. No single INS-VNTR genotype or allele was associated with an altered risk for diabetic patients.

\section{Discussion}

This is the first study of CTLA-4 and INS-VNTR Polymorphisms in persons with diabetes mellitus and its as-

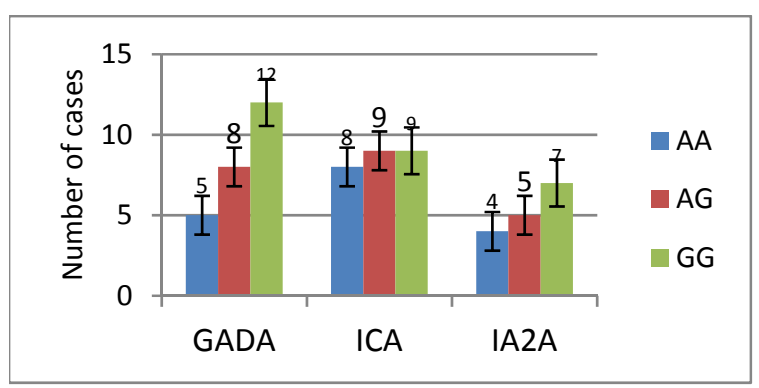

Fig. 1. Frequency of CTLA-4 AA, AG and GG Genotype in Autoantibody Positive T2DM Patients

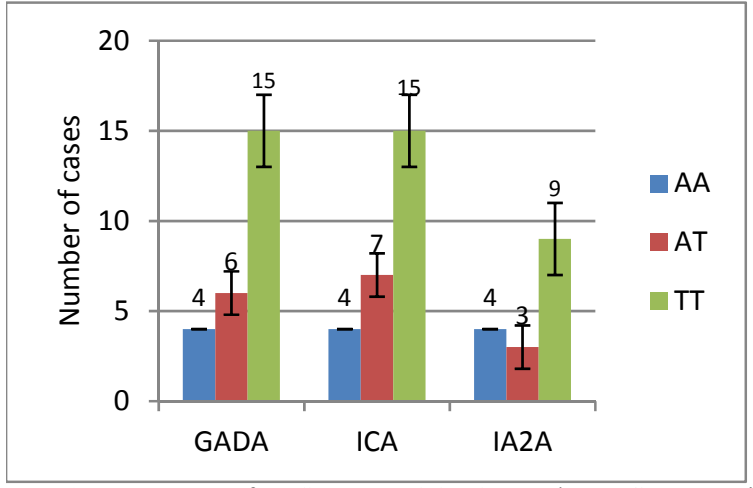

Fig. 2. Frequency of INS-VNTR AA, AT and TT Genotype in Autoantibody Positive T2DM Patients

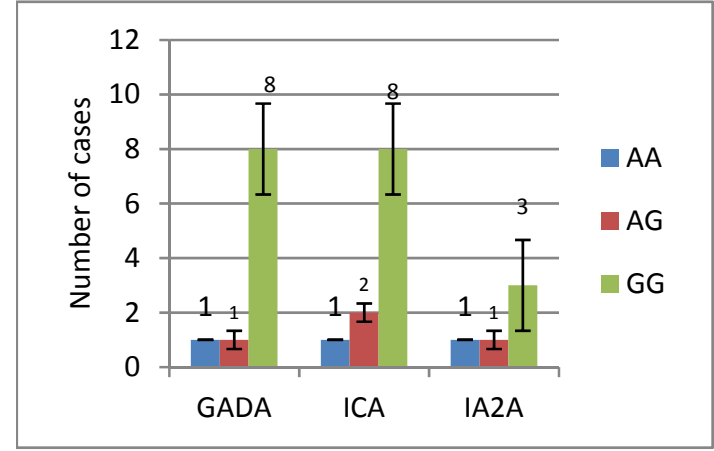

Fig. 3. Frequency of CTLA-4 AA, AG and GG Genotype In Autoantibody Positive T1DM Patients

sociation with islet autoantibodies in the Iranian population. Our results do not support the complete involvement of the CTLA-4 or INS-VNTR genes in the pathogenesis of diabetes in our population. This is inconsistent with positive associations that have been reported for the $-23 \mathrm{~A} / \mathrm{T}$ INS-VNTR and $+49 \mathrm{~A} / \mathrm{G}$ CTLA-4 polymorphisms in case-control studies in other population.

Based on classification of diabetes by Nora Hosszufalusi et al. we think our antibody positive T2DM patients are LADA. When the onset of disease is 35 years of ages or above, any circulating islet cell specific autoantibody (ICA, GADA, or IA-2A) is present, and insulin therapy is not indicated in the first 6 months after the diagnosis but needs to be treated with insulin in the early phase of the disease course, the diagnosis of LADA is established (16).

Chronic low-grade inflammation, which is present in both T1DM and T2DM, contributes to the pathogenesis of insulin resistance. The gathering of activated innate immune cells in metabolic tissues results in release of inflammatory cytokines, which promote systemic insulin resistance and beta cell destruction (17). We think at least in some of the antibody positive T2DM patients, presence of antibody is secondary to disease and chronic inflamma- 
tion provoke production of autoantibodies and activation of cell mediated immunity. In fact, these patients are T2DM but not LADA and obesity, disease duration and other factors such as epitope spreading due to chronic inflammation damages the beta cells and causes antibody production.

Patients with LADA share a genetic susceptibility with both T1DM and T2DM patients (18). In addition to HLA, studies have shown variation in two other genes increasing the risk of developing the disease. These are INSVNTR and CTLA-4. Together, these two genes confer an inheritable disease risk no larger than $15 \%(19,20)$. The insulin gene (INS) region is a predisposing locus (Insulin Dependent Diabetes Mellitus 2, IDDM2) to T1DM and LADA. This association is regulated by the polymorphism in VNTR, which categorized into three classes: I, II and III. Of these VNTRs, class I has 26-63 repeats and class III has 141-209 repeats. These are almost completely concordant with the adjacent $\mathrm{A}$ to $\mathrm{T}$ polymorphism at the -23 HphI site of insulin gene (rs689). The latter is therefore used as surrogate for class I and III INS-VNTR alleles. The INS-VNTR class I allele (-23 HphI A allele) is mostly responsible for the association of INS with autoimmune diabetes. A few studies was shown that it might be associated with T2DM and decreased insulin secretion in this patients, but these findings were challenged by other researchers (21). In Czech Republic, Matejkova-Behanova M et al., 2004 (22), Argentina, Cerrone GE et al. 2004 (24-23) and UK, Desai M., 2006 (24) positive association between an allele of -23 A/T INS-VNTR and LADA has been reported. Our results showed that SNP A/T of INS gene was not significantly associated with the risk of T1DM and antibody positive T2DM. Oindrila Raha et al. 2011 was shown that the INS gene rs689 did not have a key role in conferring the risk in T1DM patients in Indian population (25). Also, Cejkova $\mathrm{P}$ et al. showed that the genotype and allele frequencies of $-23 \mathrm{HphI}$ did not differ between T1DM, LADA and T2DM groups and group of healthy subjects in population of the Czech Republic (26). In addition to INS-VNTR, variation in several other genes contributes to diabetes pathogenesis. Architecture of HLA-conferred susceptibility to LADA is similar to that observed in T1DM (27). Variation in other genes may explain difference of disease onset in T1DM and LADA. Vatay A et al., 2002, concluded that the low presence of TNF2 allele (known to be associated with high amount of TNF alpha production) in LADA could be one of the factors responsible for the relatively slow progression (28). Polymorphism in INS-VNTR not only contributes to T1DM and LADA but also may participate in pathogenesis of T2DM $(14,40)$. Significant association between INS-VNTR genotype and both insulin sensitivity and secretion were clearly visible in infancy. Class III / III infants secreted more insulin than I / I infants and heterozygous individuals exhibiting intermediate values. The insulin levels might interact with childhood appetite and nutrition to impact the development of childhood obesity and insulin resistance (14). High frequency of protective TT genotype $(67.5 \%)$ of INS-VNTR in obese (BMI: 30.63 ) antibody negative T2DM patients may confirm role of class III in pathogenesis of disease in antibody negative T2DM patients. However, we did not find statistical difference between study groups. Our observation that GADA, ICA and IA2A do not have association with -23 $\mathrm{A} / \mathrm{T}$ INS-VNTR is consistent with Jinko Graham observation (29). In fact, the observation that IAA but not GADA and IA-2A were associated with the $-23 \mathrm{~A} / \mathrm{T}$ INS-VNTR polymorphisms suggests that the contribution of the INSVNTR may be specific to insulin as an autoantigen (29, 30).

CTLA-4 gene variation has been suggested to be risk factor of autoimmune endocrine disorders. CTLA- 4 by inducing the antigen specific apoptosis of $\mathrm{T}$ cells and prevents autoreactive proliferation of $\mathrm{T}$ lymphocytes, plays a key role in autoimmunity. It has been reported to confer genetic susceptibility to autoimmune diseases including T1DM, thyroid disorders, rheumatoid arthritis, Addison's disease, primary biliary cirrhosis, myasthenia gravis and lupus erythematous (31). The polymorphisms of the CTLA-4 gene also are associated with LADA and T2DM, and the effect of the $G$ allele on LADA is stronger than on T2DM (32). In this study, we did not find a statistically significant association between $+49 \mathrm{~A} / \mathrm{G}$ polymorphism of CTLA-4 gene and T1DM, antibody positive T2DM and healthy controls. However, GG genotype and $\mathrm{G}$ allele tend to increase in both T1DM and antibody positive T2DM groups when compare with controls. Many studies have demonstrated there is an association between $+49 \mathrm{~A} / \mathrm{G}$ CTLA-4 polymorphism and T1DM (33) and LADA (3436) and a few studies fail to show any association between +49 A/G CTLA-4 polymorphism and T1DM $(37,38)$ or LADA (39). These conflicting results may be explained by the genetic variation among the studied populations, different environmental factors and limitations of the studies or other methodological issues. On the basis of the frequency of the $G$ allele the attributable fraction of T1DM due to this polymorphism is 18 percent in populations of Asian descent and 16 percent in populations of European descent (41).

With increasing CTLA-4 G allele and GG/AG genotypes the frequency of persons who are positive for GADA, ICA and IA2A in T1DM and antibody positive T2DM patients were increased. But we did not find a statistically significant association between +49 A/G polymorphism of CTLA-4 genotypes and islet autoantibodies. Our finding was similar to other studies (31). In consistent with Robert Hermann and co-worker study, we suggest $+49 \mathrm{~A} / \mathrm{G}$ polymorphism of CTLA-4 has no a major impact on humoral autoimmunity in T1DM and LADA (30).

We found significant association between +49 A/G polymorphism of CTLA-4 genotypes and alleles and antibody negative T2DM. Similar to Azza M Kamel and coworker (36), we suggest that CTLA-4 is significantly associated with autoimmune thyroid disease (AITD) but not with T1DM; because of the strong association of AITD and T1DM, the association of CTLA-4 polymorphism with T1DM may be secondary to its association with AITD. Also, we saw G allele of $\mathrm{A} / \mathrm{G}+49 \mathrm{CTLA}-4$ had a direct proportion with familial history of diabetes (data have not shown). 
In conclusion our results using this methodology suggest that susceptibility allele A of $-23 \mathrm{~A} / \mathrm{T}$ INS-VNTR does not have role in pathogenesis of disease in our patients and susceptibility allele $\mathrm{G}$ of $+49 \mathrm{~A} / \mathrm{G}$ CTLA- 4 if not, had a small role in pathogenesis of diabetes in T1DM and antibody positive T2DM and in spite of significant increased in antibody negative T2DM group, it does not have any role in disease pathogenesis since we did not humoral immunity response and autoantibody production. We recommend similar studies with larger sample size and, if possible, the evaluation of $\mathrm{C}$ - peptide and Insulin Autoantibody (IAA) in combination with genetic analysis.

\section{Acknowledgments}

This study was done by a grant by Iran University of Medical Sciences number: 17032. We thank Naser Kalhor at the Jihad Daneshgahi Infertility Treatment Center, Stem Cell laboratory, Qom, Iran.

\section{Conflict of Interests}

The authors declare that they have no competing interests.

\section{References}

1. Paschke A, Grzelka A, Zawada A, Zozulińska-Ziółkiewicz D. Clinical characteristics and autoantibody pattern in newly diagnosed adult onset autoimmune diabetes. Polskie Archiwum Medycyny Wewnetrznej. 2013;123(7-8):401-408.

2. Bandurska-Stankiewicz E, Praszkiewicz I, Surdykowski L. Latent autoimmune diabetes in adults - LADA diabetes. Diabetologia Doswiadczalnai Kliniczna. 2006;6(4):173-181

3. Matejkova-Behanova M, Vankova M, Hill M, Kucera P, Cinek O, Andel M, Bendlova B. Polymorphism of INS VNTR is associated with glutamic acid decarboxylase antibodies and postprandial Cpeptide in patients with onset of diabetes after 35 years of age. Physiol Res. 2004;53(2):187-190

4. Desai M, Zeggini E, Owen KR, Holman RR, Levy JC, Hattersley AT, et al. Susceptibility for latent autoimmune diabetes in adults (LADA) is determined by variation at the IDDM2 (insulin-gene) locus in white Caucasian patients from UK repositories. Diabetologia. 2005;48:Suppl1:A86.

5. Bell GI, Horita S, Karam JH. A polymorphic locus near the human insulin gene is associated with insulin-dependent diabetes mellitus. Diabetes. 1984;33:176-183.

6. Stead JD, Buard J, Todd JA, Jeffreys AJ. Influence of allele lineage on the role of the insulin minisatellite in susceptibility to type 1 diabetes. Hum Mol Genet 2000; 9: 2929 -2935

7. Balic I, Angel B, Codner E, Carrasco E, Perez-Bravo F. Association of CTLA-4 polymorphisms and clinical-immunologic characteristics at onset of type 1 diabetes mellitus in children. Human Immuno. 2009;70:116-120.

8. Douroudis K, Prans E, Uibo R. CTLA-4 promoter polymorphisms are associated with latent autoimmune diabetes in adults. Human Immunology. 2009;70:921-924.

9. Kantarova D, Buc M. Genetic susceptibility to type 1 Diabetes Mellitus in Humans. Physiol Res. 2007;56:255-266

10. Anjos SM, Tessier MC, Polychronakos C. Association of the Cytotoxic T Lymphocyte-Associated Antigen 4 Gene with Type 1 Diabetes: Evidence for Independent Effects of Two Polymorphisms on the Same Haplotype Block. The Journal of Clinical Endocrinology \& Metabolism. 2004;89(12):6257-6265

11. Ahmadi S, Rostamzadeh J, Khosravi D, Shariati P and Shakiba N. Association of CTLA-4 gene 49 A/G polymorphism with the incidence of type 1 diabetes mellitus in the Iranian Kurdish population. Pakistan Journal of Biological Sciences. 2013;16(24): 1929-1935.

12. Cerna M, Novota P, Kolostova K, Cejkova P, Zdarsky E, Novakova $\mathrm{D}$, et al. HLA in Czech adult patients with autoimmune diabetes mellitus: comparison with Czech children with type 1 diabetes and patients with type 2 diabetes. Eur J Immunogenet. 2003;30(6):401-7.

13. Suguna S, Nandal DH, Kamble S, Bharatha A, Kunkulol R. Genomic DNA isolation from human whole blood samples by non enzymatic salting out method. International Journal of Pharmacy and Pharmaceutical Sciences. 2014;6(6):198-199.

14. Bazaes RA, Petry CJ, Ong KK, Avila A, Dunger DB, Mericq MV. Insulin gene VNTR genotype is associated with insulin sensitivity and secretion in infancy. Clinical Endocrinology. 2003; 59(5):599603.

15. Ferreira AC, Gomes KB, Sampaio IB, Oliveira VC, Pardini VC, Godard AL. Type 1 diabetes susceptibility determined by HLA alleles and CTLA-4 and insulin genes polymorphisms in Brazilians. Arq Bras Endocrinal Metab. 2009;53(3):368-373.

16. Hosszufalusi N, Vatay A, Rajczy K, Prohaszka Z, Pozsonyi E, Horvath L, et al. Similar genetic features and different islet cell autoantibody pattern of latent autoimmune diabetes in adults (LADA) compared with adult-onset type 1 diabetes with rapid progression. Diabetes Care. 2003;26:452-457.

17. Justin I. Odegaard and Ajay Chawla. Connecting Type 1 and Type 2 Diabetes through Innate Immunity. Cold Spring Herb Perspect Med. 2012;2:a007724.

18. Andersen MK, Lundgren V, Turunen JA, Forsblom C, Isomaa B, Groop PH, Groop L, Tuomi T. Latent autoimmune diabetes in adults differs genetically from classical type 1 diabetes diagnosed after the age of 35 years. Diabetes Care. 2010;33:2062-2064.

19. Anjos S, Polychronakos C. Mechanisms of genetic susceptibility to type I diabetes: beyond HLA. Mol Genet Metab. 2004;81:187-195.

20. Abou El-Ella SS, Shaltout AA, Tawfi MAM, Deeb M, EL-Lahony DM, Khatab ES, et al. Non HLA genetic markers association with type-1 diabetes mellitus. The Egyptian Journal of Medical Human Genetics. 2011;12:39-47.

21. D'Aleo V, Del Guerra S, Groves C, Lupi R, Tancredi M, McCarthy $\mathrm{M}$, Marchetti P. INS VNTR class genotype and the function of isolated human islets. Nutrition, Metabolism \& Cardiovascular Diseases. 2011;21(3):e9-11.

22. Matejkova-Behanova M, Vankova M, Hill M, et al. Polymorphism of INS VNTR is associated with glutamic acid decarboxylase antibodies and postprandial C-peptide in patients with onset of diabetes after 35 years of age. Physiol Res. 2004;53:187-190.

23. Cerrone GE, Caputo M, Lopez AP, Gonzalez C, Massa C, Cedola N, et al. Variable number of tandem repeats of the insulin gene determines susceptibility to latent autoimmune diabetes in adults. Mol Diagn. 2004;8(1):43-49.

24. Desai M, Zeggini E, Horton VA, Owen KR, Hattersley AT, Levy $\mathrm{JC}$, et al. The variable number of tandem repeats upstream of the insulin gene is a susceptibility locus for latent autoimmune diabetes in adults. Diabetes. 2006;55:1890-1894.

25. Raha O, Sarkar BN, Bhaskar LVKS, Veerraju P, Chowdhury S, Mukhopadhyay S, et al. Insulin (INS) promoter VNTR polymorphisms: interactions and the association with type 1 diabetes mellitus in Bengali speaking patients of Eastern India. Diabetoligia Croatica 2011;40:99-106.

26. Cejkova P, Novota P, Cerna M, Kolostova K, Novakova D, Kucera $P$, et al. HLA DRB1, DQB1 and insulin promoter VNTR polymorphisms: interactions and the association with adult-onset diabetes mellitus in Czech patients. Int J Immunogenet. 2008; 35(2):133-140.

27. Desai M, Zeggini E, Horton VA, et al. An association analysis of the HLA gene region in latent autoimmune diabetes in adults. Diabetologia 2007; 50: 68-73

28. Vatay Á, Rajczy K, Pozsonyi É, Hosszúfalusi N, Prohászka Z, Füst $\mathrm{G}$, et al. Differences in the genetic background of latent autoimmune diabetes in adults (LADA) and type 1 diabetes mellitus. Immunol Lett. 2002;84:109-115.

29. Graham J, Hagopian WA, Kockum I, Li LS, Sanjeevi CB, Lowe $\mathrm{RM}$, et al. Genetic effects on age-dependent onset and islet cell autoantibody markers in type 1 diabetes. Diabetes. 2002;51(5): 1346-55.

30. Hermann R, Laine AP, Veijola R. The effect of HLA class II, insulin and CTLA4 gene regions on the development of humoral beta cell autoimmunity. Diabetologia. 2005;48:1766-1775.

31. Douroudis K, Prans E, Kisand K, Nemvalts V, Uibo R. Cytotoxic Tlymphocyte antigen 4 gene polymorphisms are associated with latent autoimmune diabetes in adults. Clinica Chimica Acta. 2009;403:226228.

32. Qi X, Wang J, Xu Z, Sun J, Keller L, Xu W. Relationship of CTLA4 gene to latent autoimmune diabetes in adults and Type 2 diabetes: a 
population-based case-control study. Diabetes Management. 2014;4(2):131-139.

33. Mojtahedi Z, Omrani GR, Doroudchi M, Ghaderi A. CTLA-4 +49 $\mathrm{A} / \mathrm{G}$ polymorphism is associated with predisposition to type 1 diabetes in Iranians. Diabetes Res Clan Pract. 2005;68:111-6.

34. Haller K, Kisand K, Pisarev H, Salur L, Laisk T, Nemvalts V, et al. Insulin gene VNTR, CTLA-4 +49 A/G and HLA-DQB1 alleles distinguish latent autoimmune diabetes in adults from type 1 diabetes and from type 2 diabetes group. Tissue Antigens. 2007;69(2):121127.

35. Jin P, Xiang B, Huang G, Zhou Z. The association of cytotoxic Tlymphocyte antigen- $4+49 \mathrm{~A} / \mathrm{G}$ and CT60 polymorphisms with type 1 diabetes and latent autoimmune diabetes in Chinese adults. J Endocrinol Invest. 2015;38(2):149-54.

36. Cosentino A, Gambelunghe G, Tortoioli C, Falorni A. CTLA-4 gene polymorphism contributes to the genetic risk for latent autoimmune diabetes in adults. Ann N Y Acad Sci. 2002;958:337 -340.

37. Kamel AM, Mira MF, Mossallam GI, Ebid GTA, Radwan ER, AlyEldin $\mathrm{NH}$, et al. Lack of association of CTLA- $4+49$ A/G polymorphism with predisposition to type 1 diabetes in a cohort of Egyptian families. The Egyptian Journal of Medical Human Genetics. 2014; $15: 25-30$.

38. Çelmeli F, Türkkahraman D, Özel D, Akçurin S, Yegin O. CTLA-4 $(+49 \mathrm{~A} / \mathrm{G})$ Polymorphism and Type-1 Diabetes in Turkish Children. J Clin Res Pediatr Endocrinol. 2013;5(1):40-43.

39. Horton VA, Stratton IM, Owen R, Holman RR, Levy JC, Clark A. Variation at the insulin VNTR locus but not the CTLA-4 locus is associated with age of onset and need for insulin therapy in latent autoimmune diabetes in adults (LADA). Diabetologia. 2001;44: Suppl $1:$ A75.

40. Eriksson J, Osmond C,Forsen J, Kajantie E, Barker DeJP, Laakso M. Insulin Gene Variable Number of Tandem Repeat Genotype, Early Growth and Glucose Metabolism in Adult Life. Int J Endocrinol Metab. 2006;4:180-187.

41. Kavvoura FK, Ioannidis JP. CTLA-4 Gene Polymorphisms and Susceptibility to Type 1 Diabetes Mellitus: A HuGE Review and Meta-Analysis. Am J Epidemiol. 2005;162:3-16. 